\title{
Leitões recém-desmamados alimentados com dietas contendo proteína láctea e zinco suplementar
}

\author{
Marcos Livio Panhoza Tse ${ }^{1}$, Leandro Batista Costa ${ }^{1}$, Débora Barbosa Braz ${ }^{2}$, Alexandra \\ Natália Garcia ${ }^{2}$, Bernardo Berenchtein ${ }^{2}$, Valdomiro Shigueru Miyada ${ }^{3}$
}

\footnotetext{
1 Doutorando do Curso de Ciência Animal e Pastagens - ESALQ/USP.

2 Mestrando do Curso de Ciência Animal e Pastagens - ESALQ/USP.

${ }^{3}$ Departamento de Zootecnia-ESALQ/USP.
}

RESUMO - Avaliaram-se os efeitos da utilização de proteína láctea ou zinco suplementar na dieta sobre o desempenho, os pesos relativos do intestino delgado e fígado, a morfologia intestinal e as concentrações séricas de IGF-I (fator de crescimento semelhante à insulina), hormônio do crescimento e zinco em leitões. O experimento teve duração de 14 dias e foi realizado com 60 leitões desmamados aos 21 dias de idade $(5,43 \pm 0,46 \mathrm{~kg})$, em delineamento de blocos casualizados, em fatorial $2 \times 2$, composto de dois níveis de proteína láctea (com e sem, 4\%) e dois de zinco (com e sem, 2.250 ppm) na dieta. No período de 1 a 7 dias de experimento, o zinco proporcionou melhor conversão alimentar e, no período de 1 a 14 dias, promoveu maior pesos aos 14 dias e maior ganho de peso. O fornecimento de proteína láctea na dieta piorou a conversão alimentar nas duas fases (de 1 a 7 dias e de 1 a 14 dias de experimento) e resultou em menor profundidade de cripta no jejuno aos 7 dias e maior altura de vilosidade aos 14 dias de experimento. Aos 7 dias de experimento, Houve interação proteína láctea e zinco para a relação altura de vilosidades:profundidade de criptas do jejuno, a qual foi também maior nos animais recebendo proteína láctea. A adição de zinco na dieta reduziu a concentração de IGF-I e o peso relativo do fígado aos 14 dias de experimento, enquanto o uso de proteína láctea aumentou a concentração de IGF-I. A inclusão de proteína láctea melhorou a conversão alimentar, influenciou a morfologia intestinal e aumentou a concentração de IGF-I, mas a suplementação de zinco não foi eficiente para alterar os níveis de hormônio do crescimento no organismo.

Palavras-chave: IGF-I, morfologia intestinal, órgãos, produto lácteo, vilosidades

\section{Weaned piglets fed diets with milk protein and supplemental zinc}

\begin{abstract}
It was evaluated the effects of using milk protein or supplemental zinc in the diet on performance, relative weights of small intestine and liver, intestine morphology and IGF-I (insulin-like growth factor) serum concentrations, growth hormone and zinc in piglets. The experiment lasted 14 days and it was carried out using 60 piglets weaned at 21 days of age $(5.43 \pm 0.46 \mathrm{~kg})$ in a complete random design, in a $2 \times 2$ factorial composed of two levels of milk protein (with and without, $4 \%$ ) and two levels of zinc (with or without, 2,250 ppm) in the diet. In the 1-7 day experiment period, zinc provided better feed conversion and the in the 1-14 day experiment period, it promoted higher body weight at 14 days and higher weight gain. Supply of milk protein in the diet worsened feed conversion in the two phases (from 1 to 7 days and from 1 to 14 days of the experiment) and it resulted in a lower crypts depth in the jejunum and a higher villous height on day 14 of the experiment. On the $7 \underline{\text { th }}$ day of the experiment, there was an interaction among milk protein and supplemental zinc for villous height:crypts depth relationship, which was also higher for animals fed milk protein. The addition of zinc in the diet reduced insuline-like growth factor concentration and the average weight of the liver on day 14 of the experiment while the use of milk protein increased IGF-I concentrations. The inclusion of milk protein improves feed conversion, affects intestine morphology and increases IGF-I concentration, but supplementation of zinc is not efficient to affect levels of growth hormone in the organism.
\end{abstract}

Key Words: dairy product, IGF-I, intestine morphology, organs, villi

\section{Introdução}

O leite, em suas diversas formas físicas, é um alimento complexo e contém uma infinidade de substâncias bioativas (Schanbacher et al., 1998), além de sua alta digestibilidade e qualidade nutricional. Alguns fatores de crescimento presentes no colostro e no leite, como EGF, IGF-I, IGF-II, promovem o desenvolvimento natural pós-natal do intestino de animais neonatos, podendo incrementar o seu desempenho. 
Esses peptídeos bioativos, presentes no leite, são inativos dentro da sequência de aminoácidos da proteína e podem ser liberados por hidrólise enzimática durante a digestão gastrintestinal, tornando-se compostos reguladores com atividade hormonal (Meisel, 1998). Dentre os principais peptídeos bioativos, o IGF-I pode resistir à digestão e chegar em concentrações suficientes no intestino para se ligar aos seus receptores (Odle et al., 1996), promovendo o crescimento e a recuperação do epitélio intestinal. Existe, também, a hipótese de que o crescimento do organismo de maneira geral é estimulado pelo hormônio do crescimento (GH), que se liga aos seus receptores no fígado e estimula a produção de IGF-I (Edmondson et al., 2003). Um mineral importante utilizado na dieta de leitões é o zinco, o qual é importante na síntese, no armazenamento e na secreção de hormônios (Gomes et al., 2008). A hipófise, por sua vez, contém alta concentração de zinco e é fonte de hormônio do crescimento, um regulador primário do crescimento.

Doses farmacológicas de zinco ( $\mathrm{ZnO}$ ) são adicionadas às dietas de leitões para melhorar o crescimento (O’Dell, 2000). Após o desmame, a anorexia e a reduzida ingestão de energia, associadas a dietas sem zinco, podem ser a causa da diminuição dos níveis de IGF-I plasmáticos (MaCdonald, 2000), e a alta ingestão de zinco pelos leitões implica em aumento desse mineral no plasma (Williams et al., 2005).

Poucos são os estudos sobre a concentração plasmática de hormônio do crescimento e IGF-I em função da adição de zinco suplementar na dieta de leitões. Também, a possibilidade dos fatores de crescimento (IGF-I) presentes nos produtos lácteos, juntamente com o zinco, melhorarem o desempenho e ajudarem o desenvolvimento dos leitões por intermédio da recuperação do epitélio intestinal pósdesmame é desconhecida. Dessa forma, realizou-se este trabalho com o objetivo de estudar os efeitos da suplementação de proteína láctea e zinco na dieta sobre desempenho, o peso do fígado e do intestino delgado, a morfologia intestinal e as concentrações séricas de IGF-I, hormônio do crescimento e zinco de leitões em crescimento.

\section{Material e Métodos}

O experimento foi realizado nas instalações experimentais de creche do Setor de Suinocultura do Departamento de Zootecnia da ESALQ/USP. Os animais foram alojados em baias metálicas suspensas de creche, com área de 1,80 $\mathrm{m}^{2}(1,20 \mathrm{~m} \times 1,50 \mathrm{~m})$, equipadas com bebedouro do tipo chupeta e campânulas de aquecimento. O piso das baias era semirripado, com piso metálico vazado embaixo dos bebedouros e compacto (concreto) abaixo dos comedouros. Foram utilizados 60 leitões (metade macho e metade fêmea) da genética Topigs, recém-desmamados, com média de 21 dias de idade e peso inicial de 5,43 $\pm 0,46 \mathrm{~kg}$. $\mathrm{O}$ delineamento experimental foi o de blocos casualizados, em arranjo fatorial $2 \times 2$, com dois níveis de proteína láctea (com e sem a inclusão de $4 \%$ de proteína láctea) e dois de zinco suplementar (com e sem inclusão de 2.250 ppm), conforme especificado a seguir: dieta basal constituída de milho e farelo de soja, sem proteína láctea e sem zinco suplementar (2.000 ppm (ZnO) + 250 ppm de zinco (zincoaminoácidos)); dieta basal sem proteína láctea e com zinco suplementar; dieta basal com proteína láctea e sem zinco suplementar; dieta basal com proteína láctea e com zinco suplementar. A dieta experimental (pré-inicial), isonutritiva e formulada com base em Rostagno et al. (2005), foi fornecida à vontade aos animais do $21^{\circ}$ (desmame) ao $35^{\circ}$ dia de idade, correspondendo ao período experimental de 14 dias (Tabela 1). As unidades experimentais (baias) eram constituídas por quatro (blocos 1 e 2), três (bloco 3) e dois animais (blocos 4 e 5).

Para realizar as coletas de amostras sangue, intestino delgado e fígado, os animais sacrificados no $7^{\circ} \mathrm{e} 14^{\circ}$ dias de idade foram selecionados de acordo com o peso vivo, peso médio, próximo da média dos blocos 1 e 2 (foram escolhidos dois animais por tratamento, sendo um animal do bloco $1 \mathrm{e}$ outro animal do bloco 2).

Os animais receberam, durante todo o período experimental (14 dias), água e ração (ração pré-inicial) à vontade. Para a determinação de ganho peso, os animais foram pesados no início $\left(1^{\circ}\right), 7^{\circ}$ e $14^{\circ}$ dias de experimento. O consumo de ração foi calculado em cada fase, por diferença entre a quantidade de ração fornecida aos animais em cada parcela e a quantidade de ração desperdiçada e que sobrou no cocho dos animais ao final de cada fase experimental. A conversão alimentar foi calculada pela relação entre o consumo de ração e o ganho de peso dos animais.

Os animais escolhidos (dois/tratamento) para a coleta foram pesados e, em seguida, colocados de dorso, expondo-se a veia cava anterior. O sangue foi coletado com seringa de $10 \mathrm{~mL}$ e agulha $7 \times 12 \mathrm{~mm}$. As amostras de sangue foram cuidadosamente transferidas para tubos de ensaio, a fim de evitar a hemólise. Os tubos de ensaio foram colocados sobre uma superfície de isopor por 30 minutos, em temperatura ambiente, para promover a coagulação do sangue. Em seguida, as amostras foram mantidas em geladeira até o momento da centrifugação a $5000 \mathrm{rpm}$ por 5 minutos, em temperatura de $25^{\circ} \mathrm{C}$, para separação do soro. O soro foi pipetado em ependorfes de plástico de um mL e conservado à temperatura de $-20^{\circ} \mathrm{C}$, e todas as amostras de soro foram enviadas ao Laboratório Álvaro (Cascavel, Paraná) para a determinação 
Tabela 1 - Composição das dietas experimentais

\begin{tabular}{|c|c|c|c|c|}
\hline \multirow[b]{3}{*}{ Ingrediente (\%) } & \multicolumn{4}{|c|}{ Proteína láctea } \\
\hline & \multicolumn{2}{|c|}{$0 \%$} & \multicolumn{2}{|c|}{$4 \%$} \\
\hline & $\begin{array}{l}\text { Sem } \\
\text { zinco }\end{array}$ & $\begin{array}{l}\text { Com } \\
\text { zinco }\end{array}$ & $\begin{array}{l}\text { Sem } \\
\text { zinco }\end{array}$ & $\begin{array}{l}\text { Com } \\
\text { zinco }\end{array}$ \\
\hline Milho moído & 40,000 & 40,000 & 40,000 & 40,000 \\
\hline Farelo de soja & 5,000 & 5,000 & 22,087 & 22,087 \\
\hline Soycomil $^{1}$ & 10,233 & 10,233 & - & - \\
\hline Soja integral extrusada & 14,000 & 14,000 & - & - \\
\hline Lactose & 10,204 & 10,204 & 4,373 & 4,373 \\
\hline Amido de milho & 8,701 & 8,701 & 6,720 & 6,720 \\
\hline Calcário & 0,200 & 0,200 & 0,145 & 0,145 \\
\hline Fosfato bicálcico & 1,974 & 1,974 & 1,899 & 1,899 \\
\hline Produto lácteo ${ }^{2}$ & - & - & 14,286 & 14,286 \\
\hline Açúcar & 2,500 & 2,500 & 2,500 & 2,500 \\
\hline Maltodextrina & 2,500 & 2,500 & 2,500 & 2,500 \\
\hline L-lisina $\mathrm{HCl}$ 78\% & 0,617 & 0,617 & 0,505 & 0,505 \\
\hline DL-metionina 99\% & 0,144 & 0,144 & 0,078 & 0,078 \\
\hline L-treonina $98,5 \%$ & 0,248 & 0,248 & 0,222 & 0,222 \\
\hline L-triptofano 98\% & 0,037 & 0,037 & 0,038 & 0,038 \\
\hline Antibiótico & 0,009 & 0,009 & 0,009 & 0,009 \\
\hline $\begin{array}{l}\mathrm{ZnO}(78 \%)+ \\
\mathrm{Zn-aminoácidos} 3\end{array}$ & - & 0,506 & - & 0,506 \\
\hline Palatabilizante & 0,008 & 0,008 & 0,008 & 0,008 \\
\hline Cloreto de colina & 0,100 & 0,100 & 0,100 & 0,100 \\
\hline Sal & 0,300 & 0,300 & 0,300 & 0,300 \\
\hline Butil-hidroxi-tolueno & 0,030 & 0,030 & 0,030 & 0,030 \\
\hline Mistura mineral ${ }^{4}$ & 0,100 & 0,100 & 0,100 & 0,100 \\
\hline Mistura vitamínica ${ }^{5}$ & 0,100 & 0,100 & 0,100 & 0,100 \\
\hline Caulim & 2,995 & 2,489 & 4,000 & 3,494 \\
\hline Composição nutricional & & & & \\
\hline $\begin{array}{l}\text { Energia metabolizável, } \\
\mathrm{kcal} / \mathrm{kg}\end{array}$ & 3.325 & 3.325 & 3.325 & 3.325 \\
\hline Proteína láctea, \% & - & - & 4,00 & 4,00 \\
\hline PB total, \% & 18,000 & 18,000 & 18,00 & 18,00 \\
\hline Cálcio, \% & 0,70 & 0,70 & 0,70 & 0,70 \\
\hline Fósforo total, \% & 0,65 & 0,65 & 0,65 & 0,65 \\
\hline Lisina digestível, \% & 1,33 & 1,33 & 1,33 & 1,33 \\
\hline Metionina digestível, \% & 0,37 & 0,37 & 0,37 & 0,37 \\
\hline Treonina digestível, \% & 0,83 & 0,83 & 0,83 & 0,83 \\
\hline Triptofano digestível, \% & 0,24 & 0,24 & 0,24 & 0,24 \\
\hline Lactose，\% & 10,00 & 10,00 & 10,00 & 10,00 \\
\hline
\end{tabular}

1 Concentrado de proteína de soja com inativação dos fatores antinutricionais.

2 Nuklospray k-59 ${ }^{\circledR}$

${ }^{3} 2.000$ ppm de zinco ( $\left.\mathrm{ZnO}\right)+250$ ppm de zinco (zinco-aminoácidos) (Availa Zn-100 ${ }^{\circledR}$ ).

${ }^{4}$ Quantidade por kg de ração: vit. A - 8000 UI; vit. $D_{3}$ - 2000 UI; vit. E - 10 mg; vit. $\mathrm{K}_{3}$ - 0,5 mg; tiamina - 1,5 mg; riboflavina - $5 \mathrm{mg}$; vit. $\mathrm{B}_{6}$ - 2 mg; vit. $\mathrm{B}_{12}-20 \mathrm{mcg}$; ácido fólico - 0,8 mg; ácido pantotênico - 12,00 mg; niacina - $25 \mathrm{mg}$; biotina $0,05 \mathrm{mg}$; selênio - 0,28 mg.

${ }^{5}$ Quantidade por kg de ração: ferro - $100 \mathrm{mg}$; cobre - $30 \mathrm{mg}$; manganês - $70 \mathrm{mg}$; zinco - $100 \mathrm{mg}$; iodo - 1,9 mg.

das concentrações de IGF-I (método de quimioluminescência) e zinco (método enzimático calorimétrico), e para o Laboratório TECSA (Belo Horizonte/MG) para a determinação de hormônio do crescimento (método de Radioimuno ensaio específico para suínos). Para o envio das amostras, foram utilizadas caixas de isopor com gelo seco, hermeticamente vedadas, para evitar descongelamento, conforme solicitação e orientação do laboratório responsável pelas análises.

Após a coleta de sangue, os animais foram insensibilizados, com o uso de corrente elétrica, e sacrificados. A cavidade abdominal foi aberta por incisão longitudinal e rapidamente todo o tubo digestivo foi retirado para a coleta de $4 \mathrm{~cm}$ do duodeno e do jejuno, com o auxílio de régua e tesoura, sendo o material preparado posteriormente para determinação de altura de vilosidade e profundidade de cripta. Também foram feitas as pesagens do intestino delgado vazio e do fígado. As amostras de $4 \mathrm{~cm}$ do duodeno foram coletadas a $5 \mathrm{~cm}$ do esfíncter pilórico e, para jejuno, as amostras de $4 \mathrm{~cm}$ foram retiradas a $1 \mathrm{~m}$ da junção íleo-cecal (sentido caudal-cranial). Todas as amostras foram fixadas em formol (10\%), conforme descrito por van Beers-Schreurs (1998), e armazenadas em recipientes plásticos para posterior envio ao laboratório e determinação da altura de vilosidade e profundidade de cripta. As amostras de intestino foram acondicionadas em líquido Bouin, fixadas em blocos de historesina e feitos cortes não seriados em três porções do corte histológico enviado (começo, meio e final) e submetidas à coloração de hematoxilina/eosina, sendo realizadas medidas em micras, utilizando-se um programa de computador ligado ao microscópio, conforme metodologia indicada pelo laboratório responsável pelas análises (Laboratório Avipa, Campinas/SP). Com os resultados das análises de morfologia intestinal e dos pesos dos órgãos e dos animais, foram calculados, respectivamente, a relação altura de vilosidade e profundidade de cripta do duodeno e do jejuno e os pesos relativos dos órgãos (em função do peso do animal). Todos os dados foram submetidos a análise de variância pelo PROC GLM (General Linear Models) do SAS (Statistical Analysis System, 2001) e as médias, comparadas pelo teste $\mathrm{F}$.

\section{Resultados e Discussão}

Não foi observada interação $(\mathrm{P}>0,05)$ entre proteína láctea e zinco suplementar nos períodos de 1 a 7 e de 1 a 14 dias de idade. Entretanto, os animais alimentados com proteína láctea apresentaram melhor $(\mathrm{P}<0,001)$ conversão alimentar no período de 1 a 7 dias (Tabela 2). Tem-se constatado que a proteína oriunda do soro do leite é qualitativamente superior à de outros produtos, como o farelo de soja e a farinha de peixe, uma vez que a disponibilidade de seus aminoácidos é alta (Bertol et al., 1996). Quando alimentados com soro de leite, observa-se melhor atividade de amilase, quimotripsina e tripsina no intestino dos leitões (Owsley et al., 1986). Com isso, pode-se ter melhor hidrólise da fração proteica e de carboidratos da dieta no intestino quando do fornecimento de soro de leite para leitões, resultando em melhor aproveitamento dos nutrientes com consequente melhora na conversão alimentar. O zinco suplementar propiciou melhor $(\mathrm{P}<0,04)$ conversão 
Tabela 2 - Desempenho dos animais na fase de creche (1 a 7 dias e de 1 a 14 dias) alimentados com dietas com proteína láctea e zinco suplementar

\begin{tabular}{|c|c|c|c|c|c|c|c|c|c|c|}
\hline & \multicolumn{4}{|c|}{ Proteína láctea } & \multicolumn{4}{|c|}{ Proteína láctea } & \multirow{3}{*}{$\begin{array}{c}\text { Proteína } \\
\text { láctea } \\
\text { X } \\
\text { Zinco } \\
\text { suplementar }\end{array}$} & \multirow{3}{*}{ CV (\%) } \\
\hline & \multicolumn{2}{|c|}{$0 \%$} & \multicolumn{2}{|c|}{$4 \%$} & \multicolumn{2}{|c|}{$0 \%$} & \multicolumn{2}{|c|}{$4 \%$} & & \\
\hline & $\begin{array}{c}\text { Sem } \\
\text { zinco }\end{array}$ & $\begin{array}{c}\text { Com } \\
\text { zinco }\end{array}$ & $\begin{array}{c}\text { Sem } \\
\text { zinco }\end{array}$ & $\begin{array}{l}\text { Com } \\
\text { zinco }\end{array}$ & $\begin{array}{l}\text { Sem } \\
\text { zinco }\end{array}$ & $\begin{array}{l}\text { Com } \\
\text { zinco }\end{array}$ & $\begin{array}{c}\text { Sem } \\
\text { zinco }\end{array}$ & $\begin{array}{l}\text { Com } \\
\text { zinco }\end{array}$ & & \\
\hline & \multicolumn{4}{|c|}{ Período de 1 a 7 dias } & \multicolumn{4}{|c|}{ Média dos fatores (1 a 7 dias $)^{1}$} & & \\
\hline Peso inicial (kg) & 5,66 & 5,53 & 5,52 & 5,54 & 5,55 & 5,53 & 5,54 & 5,54 & NS & 0,78 \\
\hline Peso aos 7 dias $(\mathrm{kg})$ & 6,66 & 6,76 & 6,57 & 6,88 & 6,71 & 6,73 & 6,62 & 6,82 & NS & 4,05 \\
\hline Ganho diário de peso (kg) & 0,16 & 0,18 & 0,15 & 0,19 & 0,17 & 0,17 & 0,15 & 0,18 & NS & 23,4 \\
\hline Consumo diário de ração (kg) & 0,23 & 0,23 & 0,19 & 0,23 & 0,23 & 0,21 & 0,21 & 0,23 & NS & 25,39 \\
\hline \multirow[t]{2}{*}{ Conversão alimentar } & 1,44 & 1,33 & 1,26 & 1,21 & $1,39 b$ & $1,24 \mathrm{a}$ & $1,53 y$ & $1,27 x$ & NS & 5,88 \\
\hline & \multicolumn{4}{|c|}{ Período de 1 a 14 dias } & \multicolumn{4}{|c|}{ Média dos fatores (1 a 14 dias) ${ }^{2}$} & & \\
\hline Peso aos 14 dias (kg) & 8,38 & 9,21 & 8,61 & 9,27 & 8,79 & 8,94 & $8,49 y$ & $9,24 x$ & NS & 9,12 \\
\hline Ganho diário de peso (kg) & 0,20 & 0,26 & 0,22 & 0,27 & 0,23 & 0,24 & $0,21 \mathrm{y}$ & $0,27 x$ & NS & 24,39 \\
\hline Consumo diário de ração (kg) & 0,34 & 0,42 & 0,36 & 0,40 & 0,38 & 0,38 & 0,35 & 0,41 & NS & 23,88 \\
\hline Conversão alimentar & 1,74 & 1,62 & 1,62 & 1,50 & $1,68 b$ & $1,56 a$ & $1,68 y$ & $1,56 x$ & NS & 6,59 \\
\hline
\end{tabular}

alimentar para o período de 1 a 7 dias. Resultados semelhantes foram encontrados por Schell \& Kornegay (1996), quando incluíram na dieta de leitões desmamados aos 26 dias de idade zinco suplementar na forma de $\mathrm{ZnSO}_{4}$ em relação a $\mathrm{ZnO}$.

No período de 1 a 14 dias, os animais que receberam dietas com proteína láctea, independentemente da inclusão de zinco suplementar, tiveram melhor $(\mathrm{P}<0,02)$ conversão alimentar em relação àqueles que receberam dietas sem proteína láctea. Também, o zinco suplementar proporcionou maior $(\mathrm{P}<0,06)$ peso dos animais aos 14 dias, maior $(\mathrm{P}<0,05)$ ganho diário de peso e melhor $(\mathrm{P}<0,02)$ conversão alimentar. A inclusão de produto lácteo, como o soro de leite na dieta de leites recém-desmamados, melhora a conversão alimentar nos períodos subsequentes (Grinstead et al., 2000). Hauptli et al. (2005) atribuíram a melhor conversão dos leitões à inclusão de lactose na dieta, haja vista que possuem alta atividade de lactase, possibilitando uma digestão mais eficiente desse carboidrato. No presente trabalho, os níveis de lactose nas dietas foram iguais, podendo-se supor que a melhora da conversão alimentar de leitões alimentados com produtos lácteos possa advir da maior digestibilidade da matéria seca, conforme resultados encontrados por Richert et al. (1994), incorrendo em melhor aproveitamento dos nutrientes da dieta.

O zinco é mineral essencial que desempenha funções metabólicas importantes como componentes de numerosas metaloenzimas e fatores de transcrição (O’Dell, 2000), propiciando, de maneira geral, maior multiplicação celular no organismo, sobretudo nos tecidos de rápida diferenciação e, consequentemente, favorecendo o crescimento do animal. O zinco, na forma orgânica complexada, pode melhorar o desempenho dos leitões desmamados por ser melhor absorvido em relação a outras fontes inorgânicas. A maior absorção do zinco melhora o aproveitamento desse mineral e de outros nutrientes da dieta, uma vez que o zinco desempenha papel fundamental na síntese de proteínas celulares e DNA (ácido desoxirribonucleico). Isso promove um aumento na multiplicação e na capacidade absortiva das células intestinais, explicando em parte a melhor conversão alimentar dos animais tratados com zinco suplementar. A melhor biodisponibilidade de zinco para os leitões favorece o funcionamento pleno das células, possibilitando a ela exercer suas funções metabólicas.

O zinco pode desempenhar papel fundamental na estrutura de algumas enzimas. Em um domínio específico dessas enzimas, o zinco promove uma volta na cadeia de polipeptídios por criar uma ponte entre as unidades de cistina e histidina dos receptores (MacDonald et al., 2000). Como esses receptores são regulados pelos domínios de zinco, a limitada disponibilidade de zinco pode prejudicar sua responsividade à célula (Bunce, 1994). Por outro lado, a melhor biodisponibilidade de zinco para os leitões favorece o funcionamento pleno das células, possibilitando a ela exercer suas funções metabólicas.

Não houve interação proteína láctea $\times$ zinco suplementar $(\mathrm{P}>0,05)$ para altura de vilosidades e profundidade de cripta, no entanto a combinação desses dois fatores influenciou a relação altura de vilosidades e profundidade de cripta do jejuno no $7^{\circ}$ dia $(P<0,09)$ (Tabela 5). Entretanto, observou-se 
efeito isolado dos fatores e os animais recebendo proteína láctea apresentaram maior $(\mathrm{P}<0,04)$ altura de vilosidade do duodeno ao $14^{\circ}$ dia de idade e menor profundidade de cripta do jejuno no $7^{\circ}$ dia de idade (Tabelas 3 e 4).

Administrando por duas semanas uma dieta somente com produtos lácteos (substitutos de leite) a leitões que receberam previamente a mesma dieta ou dieta diretamente parenteral por 4 semanas, notou-se que após esse período houve maior altura de vilosidade ileal para os animais que receberam previamente dieta parenteral (Remillard et al., 1998. De acordo com Jensen et al. (2001), as diferenças na morfologia intestinal podem ser resultado dependente

Tabela 3 - Altura de vilosidade do duodeno e do jejuno ao 7 e ao 14 dias do período experimental

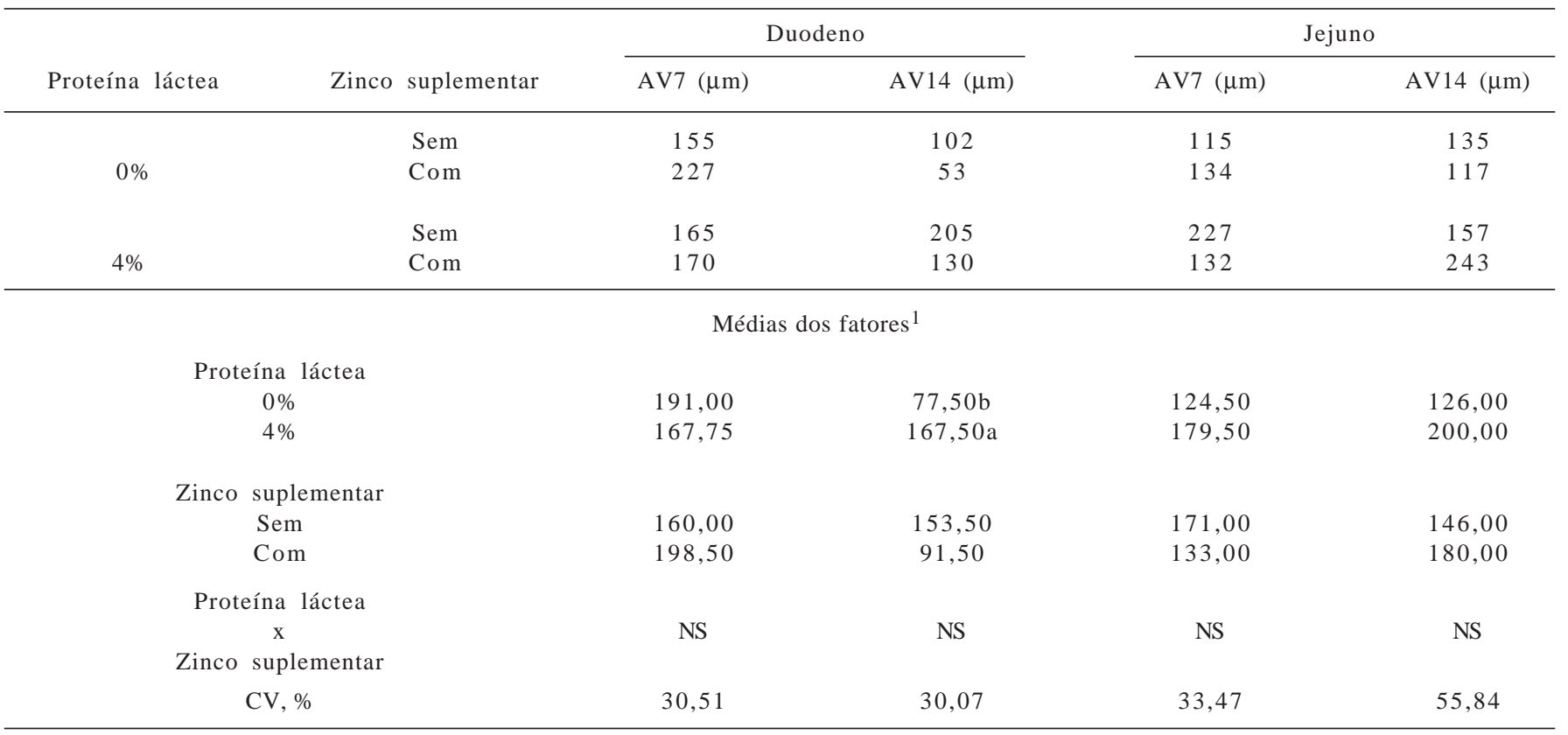

${ }^{1}$ Médias nas colunas com letras distintas para "proteína láctea” $(a, b)$ diferem $(P<0,04)$ pelo teste F.

NS = não-significativo; CV = coeficiente de variação.

Tabela 4 - Profundidade de cripta do duodeno e do jejuno ao $7^{\circ}$ e $14^{\circ}$ dias do período experimental

\begin{tabular}{|c|c|c|c|c|c|}
\hline Proteína láctea & Zinco suplementar & \multicolumn{2}{|c|}{ Duodeno } & \multicolumn{2}{|c|}{ Jejuno } \\
\hline & Sem & 40,50 & 54,00 & 39,00 & 38,50 \\
\hline $4 \%$ & Sem & 33,50 & 44,00 & 23,00 & 43,00 \\
\hline \multicolumn{6}{|c|}{ Proteína láctea } \\
\hline \multicolumn{2}{|c|}{$0 \%$} & 39,25 & 39,50 & $36,75 b$ & 34,50 \\
\hline \multicolumn{2}{|c|}{$4 \%$} & 36,75 & 41,75 & $24,75 a$ & 38,25 \\
\hline \multicolumn{6}{|c|}{ Zinco suplementar } \\
\hline \multicolumn{2}{|c|}{ Sem } & 37,00 & 49,00 & 31,00 & 40,75 \\
\hline \multicolumn{2}{|c|}{$\mathrm{CV}, \%$} & 44,66 & 66,06 & 19,91 & 44,71 \\
\hline
\end{tabular}

${ }^{1}$ Médias nas colunas com letras distintas para “proteína láctea” (a, b) diferem $(P<0,07)$ pelo teste $F$.

NS = não-significativo; CV = coeficiente de variação; $\mathrm{PC}$ = profundidade de cripta. 
Tabela 5 - Relação altura de vilosidade:profundidade de cripta (AV:PC) do duodeno e do jejuno ao $7^{\circ}$ e $14^{\circ}$ dias do período experimental

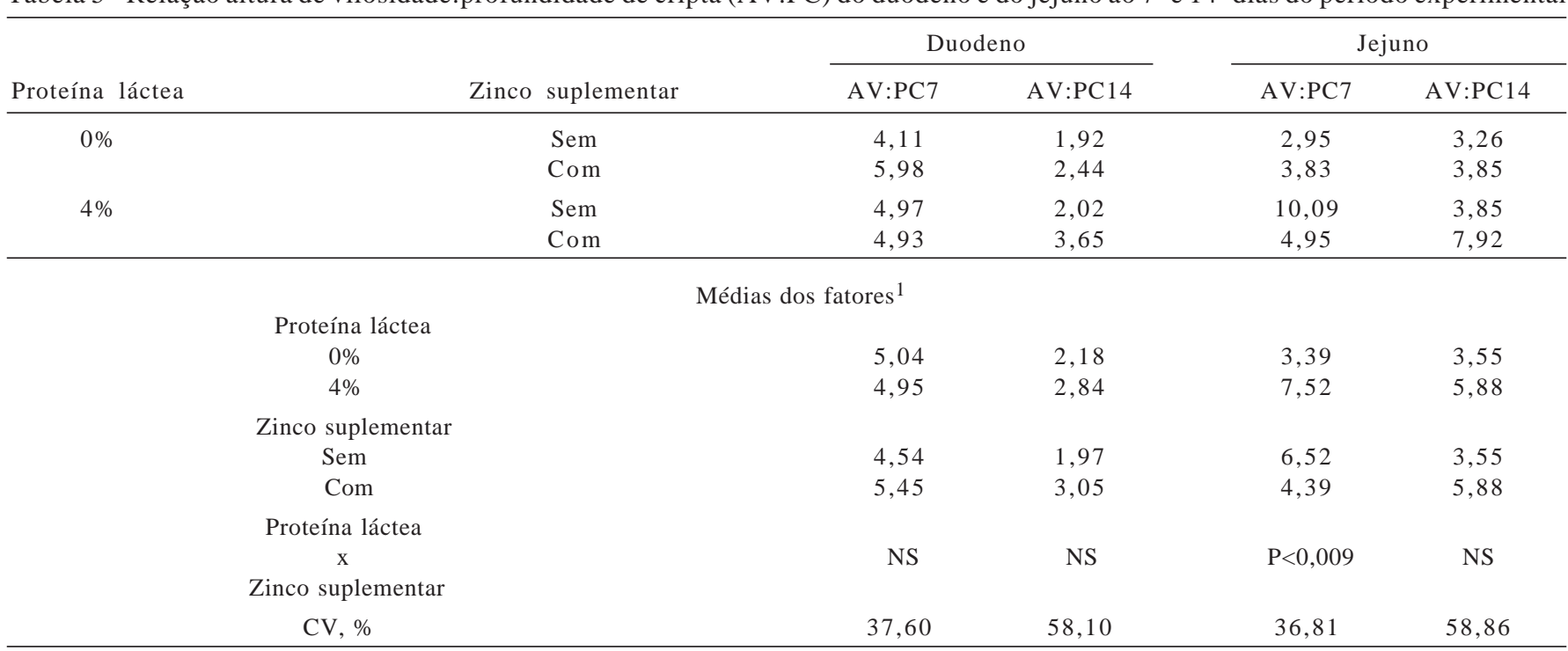

${ }^{1}$ Interação significativa $(\mathrm{P}<0,009)$ entre proteína láctea e zinco suplementar. NS = não-significativo; CV = coeficiente de variação.

diretamente da dieta, nas características bioquímicas do desenvolvimento dos enterócitos. Não é possível afirmar com exatidão se os efeitos para maior altura de vilosidades são oriundos desses fatores de crescimento presentes no leite e/ou produto lácteo, mas sugere menor injúria ou mesmo recuperação do epitélio intestinal. Para Remillard et al. (1998), pequenos volumes de leite administrados oralmente a leitões têm-se mostrado eficientes em amenizar a atrofia intestinal de suínos.

Os animais que receberam proteína láctea apresentaram $(\mathrm{P}<0,07)$ menor profundidade de cripta do jejuno ao $7^{\circ}$ dia de experimento e maior $(\mathrm{P}<0,004)$ relação altura de vilosidade e profundidade de cripta do jejuno ao $7^{\circ}$ dia de experimento. Li et al. (1991) também verificaram menor profundidade de cripta e maior altura de vilosidade quando foi administrado leite em pó desnatado para leitões, quando se comparou com o farelo de soja, o que pode sugerir menor agressão da parede intestinal pelos produtos lácteos. Também, após o desmame, ocorre naturalmente uma diminuição na quantidade de ingestão de ração, e a quantidade e a frequência de ingestão de ração pós-desmame pode ser determinante para a mantença da arquitetura das vilosidades e a integridade intestinal (Roura, 2004).

A relação altura de vilosidade e profundidade de cripta é um parâmetro importante na detecção da qualidade da mucosa intestinal, uma vez que maiores valores para essa relação indicam menor injuria da mucosa intestinal. Pluske et al. (1996) relataram maior atividade enzimática e maior absorção de nutrientes de leitões recém-desmamados recebendo leite por cinco dias após o desmame, afirmando que o leite pode influenciar os parâmetros morfométricos. Em outro estudo, leitões recém-desmamados alimentados com substitutos lácteos apresentaram maior altura de vilosidade em relação aos leitões que continuaram mamando, o que, segundo os autores, essa resposta estaria relacionada à ingestão de matéria seca (Zijlstra et al., 1996).

Entretanto, neste trabalho os animais não tiveram diferenças quanto ao consumo diário de ração entre os tratamentos ou fatores analisados isoladamente, sugerindo que a fração proteica láctea da dieta pode ter influenciado positivamente as características morfológicas do intestino dos leitões.

Para o fator zinco, os animais tiveram maior $(\mathrm{P}<0,02)$ relação altura de vilosidade e profundidade de cripta do jejuno ao $7^{\circ}$ dia de experimento. Isso pode ser evidenciado pelo papel crucial que o zinco exerce sobre a saúde intestinal, participando da integridade de membrana. Os mecanismos envolvidos com o zinco quando esse mineral é fornecido em doses farmacológicas aos leitões é o aumento de metalotioneina, uma enzima que desempenha papel fundamental na homeostase de zinco pelo sequestro desse mineral no intestino e a melhora da morfologia intestinal (Carlson et al., 1998). Assim, a maior relação altura de vilosidade e profundidade de cripta do jejuno pode refletir diretamente a funcionalidade do zinco na mantença das vilosidades intestinais.

Payne et al. (2006) encontraram maior altura de vilosidades para os animais recebendo $\mathrm{ZnO}$ em doses farmacológicas, o que reforça a ideia de menor injúria intestinal. 
Por outro lado, Mavromichalis et al. (2000) relatam que a suplementação de $\mathrm{ZnO}$ na dieta de leitões não ameniza os efeitos negativos na mucosa intestinal. Todavia, para o zinco, via dieta, exercer suas funções biológicas énecessário que sua absorção seja facilitada. Nesse contexto, minerais orgânicos complexados, como fonte de minerais, estão sendo usados como uma alternativa para melhorar a sua biodisponibilidade (Schell \& Kornegay, 1996). Assim, uma melhor absorção do mineral facilita sua ação primordial sobre as enzimas intestinais, sobre o desenvolvimento da mucosa, amenizando a injúria na mucosa intestinal que ocorre na fase pós-desmame, como mostrado neste trabalho pela maior relação altura de vilosidade e profundidade de cripta do jejuno ao $7^{\circ}$ dia de experimento.

Houve interação $(\mathrm{P}<0,009)$ dos fatores proteína láctea e zinco suplementar sobre a relação altura de vilosidade e profundidade de cripta do jejuno ao $7^{\circ}$ dia de experimento (Tabela 6). Ao considerar a inclusão de proteína láctea na ração, os animais que não receberam zinco suplementar tiveram maior $(\mathrm{P}<0,005)$ relação altura de vilosidade e profundidade de cripta do jejuno ao $7^{\circ}$ dia de experimento, e ao considerar a não inclusão de zinco suplementar os animais tiveram maior $(\mathrm{P}<0,002)$ relação quando incluída a proteína láctea.

Bertol et al. (2000) não encontraram diferença na morfologia intestinal quando da inclusão de produtos lácteos na dieta de leitões recém-desmamados. Entretanto, ao comparar dietas contendo leite em pó pela substituição crescente de subprodutos de soja, Soares et al. (2000) encontraram maior altura de vilosidade no intestino delgado e maior relação altura de vilosidade e profundidade de cripta para os leitões que receberam dietas contendo leite em pó. Segundo os autores, essa melhora na morfologia intestinal foi atribuída hipoteticamente ao fato de que o leite em pó não possui proteínas alergênicas e por conter diferentes fatores de crescimento na sua composição, promovendo a recuperação mais rápida da mucosa intestinal dos leitões após a desmama. Hedemann et al. (2006), trabalhando com doses farmacológicas de zinco, também verificaram maior altura de vilosidades.
Para o parâmetro de Hormônio do Crescimento, no presente trabalho, foi adotada a metodologia descrita por de Rodas et al. (1995), a qual descreve as coletas de sangue dos animais entre 8:00 e 9:00 da manhã, e o método de Radioimuno ensaio (RIA) para detecção dos níveis hormonais. Entretanto, a secreção de hormônio do crescimento se dá de maneira pulsátil, ocorrendo liberação de picos de hormônio do crescimento alternados com valores basais considerados previamente como indetectáveis quando medidos por radioimuno ensaio (RIA) (Casagrande \& Czeplelewski, 2007). Dessa maneira, a ausência de resultados para o hormônio do crescimento pode ser explicada pela incompatibilidade do momento da coleta com os baixos níveis séricos desse hormônio, os quais, então, não foram sensíveis ao método utilizado (Tabela 7).

Não houve interação significativa entre proteína láctea e zinco suplementar, porém os animais que receberam proteína láctea tiveram maior $(\mathrm{P}<0,001)$ concentração de IGF-I ao $14^{\circ}$ dia de experimento. A dieta com proteína láctea, fornecida aos animais deste experimento, proporcionou uma condição mais favorável de digestão dos nutrientes da dieta, possibilitando aos animais adquirir um status nutricional superior, com consequente aumento do nível de IGF-I. A digestibilidade tem correlação positiva com o consumo de leitões pós-desmame. Buonomo \& Baile (1991) mostraram que a ingestão de energia e proteína (status nutricional) pós-desmame aumenta os níveis de IGF-I.

Por outro lado, não houve influência dos tratamentos e do fator proteína láctea sobre as concentrações de IGF-I $(\mathrm{P}>0,05)$ nos demais períodos analisados. De Rodas et al. (1995), trabalhando com plasma suíno contendo IGF-I, também não observaram diferença nos níveis plasmáticos desse peptídeo. Os autores mostraram que a ausência de resultado pode ter sido advinda do fato de que tal biopeptídeo é pouco absorvido, ou mesmo os animais não ingeriram uma quantidade suficiente de ração contendo o plasma suíno com o IGF-I para aumentar/influenciar os níveis plasmáticos. Isso pode talvez, explicar em parte a ausência de resultados encontrados para os dias anteriores, uma vez que os animais têm um reduzido consumo de ração.

Tabela 6 - Interação entre proteína láctea e zinco suplementar e efeitos sobre a relação altura de vilosidade e profundidade de cripta ao $7^{\circ}$ dia de experimento

\begin{tabular}{|c|c|c|c|c|c|c|}
\hline \multirow[t]{2}{*}{ Jejuno } & \multirow[t]{2}{*}{ Proteína láctea } & \multicolumn{2}{|c|}{ Zinco suplementar } & \multirow[t]{2}{*}{ Média $^{2}$} & \multirow[t]{2}{*}{ CV (\%) } & \multirow[t]{2}{*}{ Interação $\mathrm{PL} \times \mathrm{Zr}$} \\
\hline & & Sem & Com & & & \\
\hline \multirow{3}{*}{ AV:PC 7} & $0 \%$ & 2,95aB & $3,83 \mathrm{aA}$ & 3,39 & & \\
\hline & $4 \%$ & $10,09 \mathrm{bA}$ & $4,95 \mathrm{aA}$ & 7,52 & 12,85 & $\mathrm{P}<0,009$ \\
\hline & Média $^{2}$ & 6,52 & 4,39 & & & \\
\hline
\end{tabular}

${ }^{1}$ Letras minúsculas distintas na linha $(\mathrm{P}<0,005)$ e letras maiúsculas distintas na coluna $(\mathrm{P}<0,002)$ diferem entre si, pelo teste $\mathrm{F}$.

2 Efeito de zinco suplementar $(\mathrm{P}<0,02)$ e efeito de proteína láctea $(\mathrm{P}<0,004)$.

$\mathrm{CV}=$ coeficiente de variação. 
Os animais que não receberam zinco suplementar apresentaram maior $(\mathrm{P}<0,007)$ concentração sérica de IGF-I ao $14^{\circ}$ dia de experimento. O hormônio do crescimento estimula a síntese hepática de IGF-I por associação dos receptores do hormônio do crescimento no fígado (MAcDonald, 2000). Entretanto, os dados dessa pesquisa foram inconsistentes para o hormônio do crescimento e para a maior concentração de IGF-I aos animais que não receberam zinco.

A deficiência de zinco diminui os níveis de hormônio do crescimento em ratos (Burrin et al., 1997). O aumento da inclusão de zinco na dieta pode promover o aumento dos níveis circulantes de hormônio do crescimento, uma vez que a pituitária é fonte primária desse hormônio e, portanto, o zinco melhora a função pituitária. A administração de 2.500 ppm de zinco após o desmame aumentou a concentração de zinco no plasma e na mucosa intestinal (Carlson et al., 2007).

A administração de hormônio do crescimento porcino para suínos em crescimento não mostrou resposta no crescimento dos animais (Harrell et al., 1994). Essa aparente ausência de resposta pode ser atribuída à falta de receptores hepáticos em leitões jovens (Breier et al., 1989). Esse fato pode explicar a ausência de resultados com relação ao hormônio do crescimento, em função da dieta, principalmente zinco suplementar.

Também, a ausência de resultados quanto ao hormônio do crescimento pode estar relacionada ao fato de que esse hormônio é liberado de forma pulsátil (Lee \& Anderson, s.d). Segundo os mesmos autores, a ação do hormônio do crescimento no fígado é mediada pelo IGF-I e sua secreção na forma pulsátil se deve à regulação no hipotálamo. Em fetos de suínos, a secreção de hormônio do crescimento é pulsátil e não há ritmo diurno de secreção (Bauer \& Parvizi, 1996), podendo, portanto, existir incompatibilidade das coletas efetuadas nesse experimento com os pulsos do hormônio do crescimento plasmáticos.

Não houve influência e nem interação entre os tratamentos sobre os pesos dos órgãos $(\mathrm{P}>0,05)$ em nenhum dos períodos estudados (Tabela 8). O leite, em suas diversas formas físicas, usado na dieta de leitões, é um alimento complexo e contém uma infinidade de substâncias bioativas, incluindo os fatores de crescimento (IGF-I) e suas respectivas funções (Schanbacher et al., 1998).

Burrin et al. (1999) também constataram que não há influencia sobre o peso dos órgãos de ratos alimentados com leite fortificado com IGF-I, sugerindo que tal biopeptídeo tem ação local do intestino delgado. Entretanto, o fornecimento contínuo de IGF-I a ratos adultos por 14 dias resultou em crescimento gastrintestinal, aumentando o peso relativo do intestino (Steeb et al., 1994). Ainda, o consumo de ração pós-desmame é determinante para aumentar a massa intestinal. Porém, os animais desse experimento não diferiram com relação ao consumo diário de ração, o que sugere a ideia de que a fração de proteína oriunda do leite possa ter influenciado positivamente nos resultados aos animais.

Tabela 7 - Parâmetros sanguíneos dos leitões do $7^{\circ}$ e $14^{\circ}$ dias de experimento

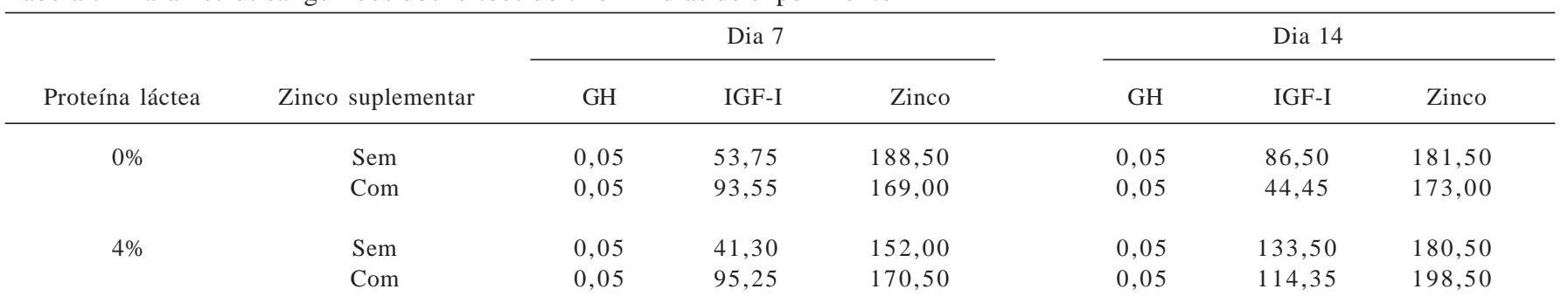

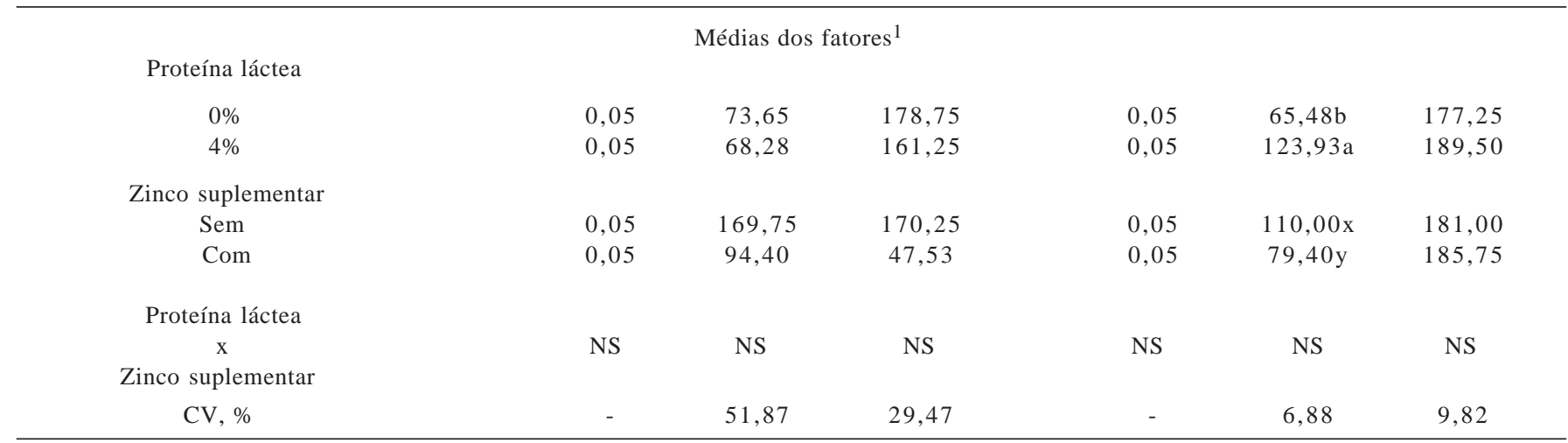

\footnotetext{
${ }^{1}$ Médias nas colunas com letras distintas para fator “proteína láctea” (a, b) e "zinco suplementar” (x, y) diferem pelo teste F, com P<0,001 e P<0,007, respectivamente.
} NS = não significativo; CV = coeficiente de variação. 
Os animais que não receberam zinco suplementar apresentaram maior peso do fígado $(\mathrm{P}<0,02)$. Sabe-se que a hipófise, fonte de produção de hormônio do crescimento, possui alta concentração de zinco, o que pode relacionarse estreitamente com as respostas de doses de zinco na dieta e níveis séricos de IGF-I. As ações de promoção de crescimento do hormônio do crescimento são presumivelmente mediadas pelo IGF-I, que é produzido no fígado (Prado et al., 2003).

Em estudo recente, a concentração hepática de zinco foi maior nos leitões alimentados com 3.000 ppm de zinco com ZnO em relação às outras dosagens (Case \& Carlson, 2002). Assim, nessa pesquisa, esperava-se, portanto, que os animais recebendo zinco apresentassem maior peso relativo desse órgão. Isso pode ser verdade, pois a timidina quinase, uma enzima cuja sua transcrição gênica acontece pela disponibilidade de zinco (MacDonald, 2000), é intrinsecamente relacionada à síntese de DNA no fígado, e que Chesters et al. (1990) observaram menores níveis de DNA em função de uma redução da atividade da enzima timidina quinase. Dietas deficientes em zinco para ratos, administradas durante cinco dias, foram suficientes para reduzir linearmente a incorporação de timidina no DNA no fígado e no baço (Williams et al., 1970). Para Case \& Carlson (2002), os mecanismos biológicos do zinco sobre a melhora do desempenho dos animais ainda é incerta.
Ao comparar fontes de zinco ( $\mathrm{ZnSO}_{4}$ e $\mathrm{Zn}$-metionina) e também a inclusão ou não desse mineral na dieta, Revy et al. (2004) não encontraram diferença sobre as concentrações hepáticas de zinco e sobre o peso do órgão. Entretanto, o fígado tem grande capacidade de acúmulo de zinco, evidenciado por maiores concentrações de zinco em tal órgão, quando da administração de $\mathrm{ZnSO}_{4}$, zinco-lisina, zinco-metionina e ZnO a leitões (Schell \& Kornegay, 1996).

Os resultados contrários dessa pesquisa podem sugerir que a ausência de zinco suplementar na dieta de leitões pode ter provocado um hipertrofia no fígado em compensação a uma possível menor atividade enzimática e redução de DNA hepático, em função do provável menor acúmulo desse mineral no fígado em relação os demais tratamentos. Também, as respostas inconsistentes com relação ao zinco podem ser explicadas pelo fato de que há utilização do zinco por outras fontes metabólicas e/ou estocagem do que propriamente associada ao fígado (Revy et al., 2002).

O modo de ação do zinco e sua associação como promotor do crescimento em leitões jovens ainda é incerta (Mavromichalis et al., 2000). Carlson et al. (1999) sugerem que a indução da metalotioneina nos enterócitos pode ser responsável para aumentar o crescimento animal sob doses farmacológicas de zinco. A metalotioneina está envolvida na homeostase do zinco no intestino delgado e nos níveis sistêmicos e, assim, essa expressão é diretamente relacionada pela concentração de zinco (Mavromichalis et al., 2000).

Tabela 8 - Pesos relativos do fígado e do intestino delgado ao $7^{\circ}$ e $14^{\circ}$ dias de experimento

\begin{tabular}{|c|c|c|c|c|c|}
\hline \multirow[b]{2}{*}{ Proteína láctea } & \multirow[b]{2}{*}{ Zinco suplementar } & \multicolumn{2}{|c|}{$7^{\circ}$ dia } & \multicolumn{2}{|c|}{$14^{\circ}$ dia } \\
\hline & & Fígado (\% PV) & Intestino delgado (\% PV) & Fígado (\% PV) & Intestino delgado (\% PV) \\
\hline \multirow[t]{2}{*}{$0 \%$} & Sem & 2,61 & 4,96 & 3,10 & 5,76 \\
\hline & Com & 2,15 & 5,70 & 2,51 & 5,38 \\
\hline \multirow[t]{2}{*}{$4 \%$} & Sem & 2,48 & 5,42 & 3,10 & 6,57 \\
\hline & Com & 2,57 & 5,83 & 2,63 & 6,36 \\
\hline \multicolumn{6}{|c|}{ Médias dos fatores ${ }^{1}$} \\
\hline \multicolumn{6}{|c|}{ Proteína láctea } \\
\hline \multicolumn{2}{|c|}{$0 \%$} & 2,38 & 5,31 & 2,80 & 5,57 \\
\hline \multicolumn{2}{|r|}{$4 \%$} & 2,53 & 5,72 & 2,87 & 6,46 \\
\hline \multicolumn{6}{|c|}{ Zinco suplementar } \\
\hline \multicolumn{2}{|c|}{ Sem } & 2,55 & 5,19 & $3,10 x$ & 6,16 \\
\hline \multicolumn{2}{|c|}{ Com } & 2,36 & 5,77 & $2,57 y$ & 5,87 \\
\hline \multicolumn{2}{|c|}{ Proteína láctea } & & & & \\
\hline & & NS & NS & NS & NS \\
\hline \multicolumn{2}{|c|}{ Zinco suplementar } & & & & \\
\hline \multicolumn{2}{|c|}{$\mathrm{CV}, \%$} & 7,30 & 10,77 & 5,87 & 8,86 \\
\hline
\end{tabular}

${ }^{1}$ Médias nas colunas com letras distintas para fator "zinco suplementar” (x, y) diferem pelo teste $\mathrm{F}(\mathrm{P}<0,02)$

NS = não significativo; CV=coeficiente de variação. 


\section{Conclusões}

A inclusão de proteína láctea na dieta influencia a altura de vilosidades e a profundidade de cripta dos animais e acarreta maior concentração de IGF-I, refletindo em melhor conversão alimentar dos animais. O zinco suplementar melhora o ganho diário de peso e a conversão alimentar dos animais aos 14 dias de experimento, mas não é eficiente para alterar os níveis de hormônio do crescimento no organismo.

\section{Agradecimentos}

À ADM do Brasil Ltda., à Corn Products Brasil Ltda., à Nutron Alimentos Ltda., à Sloten do Brasil Ltda. e à M.Cassab Comércio e Indústria Ltda, pelo fornecimento de ingredientes das dietas experimentais. Agradecimento especial à Zinpro Performance Minerals, pelo apoio financeiro nas análises de morfologia intestinal.

\section{Referências}

BAUER, M.; PARVIZI, N. Pulsatile and diurnal secretion of GH and IGF-I in the chronically catherized pig fetus. Journal of Endocrinology, v.149, p.125-133, 1996.

BERTOL, T.M.; SANTOS FILHO, J.I.; BONETT, L. Soro de leite integral na alimentação dos suínos. Suinocultura dinâmica. Concórdia: EMBRAPA, 1996. n.17. 8p.

BERTOL, T.M.; LUDKE, J.V.; MORES, N. Efeito de diferentes fontes proteicas sobre desempenho, composição corporal e morfologia intestinal em leitões. Revista Brasileira de Zootecnia, v.29, p.1735-1742, 2000.

BREIER, B.H.; GLUCKMAN, P.D.; BLAIR, H.T. et al. Somatotrophic receptors in hepatic tissue of the developing male pig. Journal of Endocrinology, v.123, p.25-31, 1989.

BUNCE, G.E. Interactions between zinc, vitamins $\mathrm{A}$ and $\mathrm{D}$ and hormones in the regulation of growth. Advances in Experimental Medicine and Biology, v.352, p.257-264, 1994.

BUONOMO, F.C.; BAILE, C.A. influence of nutritional deprivation on insulin-like growth factor I, somatotropin, and metabolic hormones in swine. Journal of Animal Science, v.69, p.755-760, 1991.

BURRIN, D.G.; DAVIS, T.A.; FIOROTTO, M.L. et al. Role of Milk-Borne vs Endogenous Insulin-Like Growth Factor I in Neonatal Growth. Journal of Animal Science, v.75, p.2739-2743, 1997.

BURRIN, D.G.; FIOROTTO, M.L.; HADSELL, D.L. Transgenic Hypersecretion of des(1-3) Human Insulin-Like Growth Factor I in Mouse Milk Has Limited Effects on the Gastrointestinal Tract in Suckling Pups. Journal of Nutrition, v.129, p.51-56, 1999.

BURRIN, D.G.; WESTER, T.J.; DAVIS, T.A. et al. Orally administered IGF-I increases intestinal mucosal growth in formula-fed neonatal pigs. American Journal of Physiology, v.270, p.R1085-R1091, 1996.

CARLSON, D.; BEATTIE, J.H.; POULSEN, H.D. Assessment of zinc and copper status in weaned piglets in relation to dietary zinc and copper supply. Journal of Animal Physiology and Animal Nutrition, v.91, p.19-28, 2007.

CARLSON, M.S.; HILL, G.M.; LINK, J.E. Early and traditionally weaned nursery pigs benefit from phase-feeding pharmacological concentrations of zinc oxide: Effect on Metallothionein and mineral concentrations. Journal of Animal Science, v.77, p.1199-1207, 1999.

CARLSON, M.S.; HOOVER, S.L.; HILL, G.M. et al. Effect of pharmacological zinc on intestinal metallothionein concentration and morphology of the nursery pig. Journal of Animal Science, v.76. (Suppl.1), p.57 (Abstr.), 1998.

CASE, C.L.; CARLSON, M.S. Effect of feeding organic and inorganic sources of additional zinc on growth performance and zinc balance in nursery pigs. Journal of Animal Science, v.80, p.1917-1924, 2002.

CHESTERS, J.K.; PETRIE, L.; TRAVIS, A.J. A requirement for $\mathrm{Zn}^{2+}$ for the induction of thymidine kinase but not ornithine decarboxylase in $3 \mathrm{~T} 3$ cells stimulated from quiescence. Biochemical Journal, v.272, p.525-527, 1990.

de RODAS, B.Z.; SOHN, K.S.; MAXWELL, C.V. et al. Plasma protein for pigs weaned at 19 to 24 days of age: Effect on performance and plasma insulin-like growth factor I, growth hormone, insulin, and glucose concentrations. Journal of Animal Science, v.73, p.3657-3665, 1995.

EDMONDSON, S.R.; THUMIGER, S.P.; WERTHER, G.A. et al. Epidermal homeostasis: the role of the growth hormone and insulin-like growth factor systems. Endocrine Reviews, v.24, p.737-764, 2003.

GOMES, P.C.; RIGUEIRA, D.C.M.; ROSTAGNO, H.S. et al. Exigências nutricionais de zinco para frangos de corte machos e fêmeas na fase inicial. Revista Brasileira de Zootecnia, v.37, n.1, p.79-83, 2008.

GRINSTEAD, G.S.; GOODBAND, R.D.; DRITZ, S.S. et al. Effects of a whey protein product and spray-dried animal plasma on growth performance of weanling pigs. Journal of Animal Science, v.78, p.647-657, 2000.

HARRELL, R.J.; THOMAS, M.J.; BOYD, D. et al. Ontogenic dependent response to exogenous porcine somatotropin in growing pigs. Journal of Animal Science, v.72. (Suppl.1), p.253, (Abstr.), 1994.

HAUPTLI, L.; LOVATTO, P.A.; SILVA, J.H.S. et al. Níveis de soro de leite integral na dieta de leitões na creche. Ciência Rural, v.35, p.1161-1165, 2005.

HEDEMANN, M.S; JENSEN, B.B.; POULSEN, H.D. Influence of dietary zinc and copper on digestive enzyme activity and intestinal morphology in weaned pigs. Journal of Animal Science, v.84, p.3310-3320, 2006.

JENSEN, A.R.; ELNIF, J.; BURRIN, D.G. et al. Development of intestinal immunoglobulin absorption and enzyme activities in neonatal pigs is diet dependent. Journal of Nutrition, v.131, p.3259-3265, 2001.

LEE, J.S.; ANDERSON, L.L. Endocrine regulation for growth in pigs. Breeding/Physiology. Iowa State University. Disponível em: <http://www.ipic.iastate.edu/reports/01swinereports/asl1778.pdf.> Acesso em: 21/6/2007.

LI, D.F.; NELSSEN, J.L.; REDDY, P.G. et al. Measuring suitability of soybean products for early-weaned pigs with immunological criteria. Journal of Animal Science, v.69, p.3299-3307, 1991.

LOUVEAU, I.; GONDRET, F. Regulation of development and metabolism of adipose tissue by growth hormone and the insulinlike growth factor system. Domestic Animal Endocrinology, v.27, p.241-255, 2004.

MacDONALD, R.S. The role of zinc in growth and cell proliferation. Journal of Nutrition, v.130, p.1500S-1508S, 2000.

MAVROMICHALIS, L.; PETER, C.M.; PARR, T.M. et al. Growthpromoting efficacy in young pigs of two sources of zinc oxide having either a high or a low bioavailability of zinc. Journal of Animal Science, v.78, p.2896-2902, 2000.

MEISEL, H. Overview on milk protein-derived peptides. International Dairy Journal, v.8, p.363-373, 1998.

O’DELL, B.L. Role of zinc in plasma membrane function. Journal of Nutrition, v.130, p.1432S-1436S, 2000 (Suppl.5S).

ODLE, J.; ZIJLSTRA, R.T.; DONOVAN, S.M. Intestinal effects of Milkborn Growth factors in neonates of agricultural 
importance. Journal of Animal Science, v.74, p.2509-2522, 1996.

OWSLEY, W.F.; ORR JR., D.E.; TRIBLLE, L.F. Effects of age and diet on the development of the pancreas and the synthesis and secretion of pancreatic enzymes in young pig. Journal of Animal Science, v.63, p.497-504, 1986.

PAYNE, R.L; BIDNER, T.D; FAKLER, T.M. et al. Growth and intestinal morphology of pigs from sows fed two zinc sources during gestation and lactation. Journal of Animal Science, v.84, p.2141-2149, 2006.

PLUSKE, J.R.; WILLIAMS, I.H.; AHERNE, F.X. Villous height and crypt depth in piglets in response to increases in the intake of cows' milk after weaning. Animal Science, v.62, p.145-158, 1996.

PRADO, I.N.; NASCIMENTO, W.G.; NEGRÃO, J.A. et al. Somatotropina Bovina Recombinante (rBST) nos Aspectos Hematológicos e Metabólitos do Sangue de Novilhas ( $1 \frac{12}{2}$ Nelore x 1/2 Red Angus) em Confinamento. Revista Brasileira de Zootecnia, v.32, p.465-472, 2003.

REMILLARD, R.L.; DUDGEON, D.L.; YARDLEY, J.H. Atrophied small intestinal responses of piglets to oral feedings of milk. Journal of Nutrition, v.128, p.2727S-2729S, 1998.

REVY, P.S.; JONDREVILLE, C.; DOURMADA, J.Y. et al. Effect of zinc supplemented as either an organic or an inorganic source and of microbial phytase on zinc and other minerals utilisation by weanling pigs. Animal Feed Science and Technology, v.116, p.93-112, 2004.

REVY, P.S.; JONDREVILLE, C.; DOURMAD, J.Y. et al. Bioavailability of two sources of zinc in weanling pigs. Animal Research, v.51, p.315-326, 2002.

RICHERT, B.T.; HANCOCK, J.D.; MORRIL, J.L. Effects of Replacing Milk and Soybean Products with Wheat Glutens on Digestibility of Nutrients and Growth Performance in Nursery Pigs. Journal of Animal Science, v.72, p.151-159, 1994.

ROSTAGNO, H.S.; ALBINO, L.F.T.; DONZELE, J.L. Tabelas brasileiras para aves e suínos: composição de alimentos e exigências nutricionais. 2.ed. Viçosa, MG: Universidade Federal de Viçosa, Departamento de Zootecnia, 2005. 186p.

ROURA, E. Changes in piglet feeding behavior at weaning: digestive development and dietary factors. In: CONGRESSO LATINO
AMERICANO DE SUINOCULTURA, 2., 2004, Foz do Iguaçu. Anais... Foz do Iguaçu: Animal World, 2004. p.115-124.

SCHANBACHER, F.L.; TALHOUK, R.S.; MURRAY, F.A. et al. Milk-born bioactive peptides. International Dairy Journal, v.8, p.393-403, 1998.

SCHELL, T.C.; KORNEGAY, E.T. Zinc concentrations in tissues and performance of weanling pigs fed pharmacological levels of zinc from ZnO, Zn-Met, Zn-Lys, or ZnSO4. Journal of Animal Science, v.74, p.1584-1593, 1996.

SOARES, J.L.; DONZELE, J.P.; OLIVEIRA, R.F.M. et al. Soja integral processada (fermentada e extrusada) e farelo de soja em substituição ao leite em pó em dieta de leitões desmamados aos 14 dias de idade. Revista Brasileira de Zootecnia, v.29, p.1153-1161, 2000.

STATISTICAL ANALYSIS SYSTEM - SAS. SAS user's guide: statistics (Version 6.12 ed.). Cary: SAS Institute, 2001. (CD-ROM).

STEEB, C.B.; TRAHAIR, J.F.; TOMAS, F.M. et al. Prolonged administration of IGF peptides enhances growth of gastrointestinal tissues in normal rats. American Journal of Physiology Gastrointestinal and Liver Physiology, v.266, p.G1090-G1098, 1994.

Van BEERS-SCHREURS, H.M.G.; NABUURS, M.J.A.; VELLENGA, $\mathrm{L}$. et al. Weaning and the weanling diet influence the villous height and crypt depth in the small intestine of pigs and alter the concentrations of short-chain fatty acids in the large intestine and blood. Journal of Nutrition, v.128, p.947-953, 1998.

WILLIAMS, R.B.; CHESTERS, J.K. The effects of early zinc deficiency on DNA and protein synthesis in the rat. British Journal of Nutrition, v.24, p.1053-1059, 1970.

WILLIAMS, S.B.; SOUTHERN. L.L.; BIDNER, T.D. Effects of supplemental dietary phytase and pharmacological concentrations of zinc on growth performance and tissue zinc concentrations of weanling pigs. Journal of Animal Science, v.83, p.386-392, 2005.

ZIJLSTRA, R.T.; WHANG, K.Y.; EASTER, R.A. et al. Effect of feeding a milk replacer to early-weaned pigs on growth, body composition, and small intestinal morphology, compared with suckled littermates. Journal of Animal Science, v.74, p.2948-2959, 1996. 